\title{
Social Movements as Communication Networks in the Information Age
}

\author{
Natalia Skobelina*, Irinz Litvinova, and Oxana Karagodina \\ Volgograd State University, Russia, Volgograd, University av., 100
}

\begin{abstract}
Mobile flexible social structures have special value. In the article, global and local social movements are investigated. On the basis of the empirical data, the importance of network movements in a modern Russian society is analyzed. Virtual movements are a new form of participating in political life. They represent complex multilevel structures which elements are distinguished by content and orientation. The global network of movements has arisen against undesirable social transformations and world economic crises. In this paper, authors use the institutional approach, analyze the sector of Russian movements and determine the mechanism of institutionalization of movements in the information and communication on the Internet in the information age.
\end{abstract}

\section{Introduction}

The interdependence of the world community has generated problems of different nature. These are being solved by both individuals and networks. Similar forms, including social protest, civic initiatives, organizations and movements are currently operating all over the world. Mobile flexible social structures have gained particular significance, individuals and unions are getting adapted rapidly to the new environment. Social movements as the subject matter of the research are a rather complex and multifaceted phenomenon. In the modern sociological science, there is a great number of definitions and interpretations of the notion in question. Modern scientists I. Jenkins, K. Ekkert, P. Sztompka, M. Woisen, A. Touraine, S. Tilly, M. Castells define specific features of new social movements. The researches carried out by P. Berger, S. Huntington, H. Kelner, H.-G. Zofner, T. Sidorina, T. Polyannikova, V. Filatova, O. Yanitskiy and other authors are of special interest to the current work, where a significant role of global network movements structuring the new reality is emphasized in the information age. M. Castells "examines the social, cultural and political roots of these new social movements, their innovative forms of selforganization". He suggests "an exploration of the new forms of social movements and protests that are erupting in the world today, from the Arab uprisings to the indignant movement in Spain, and the Occupy Wall Street movement in the US", examines "the reasons for the support they have found in large segments of society, and probes their capacity to induce political change by influencing people's minds" [1].

In this paper, authors use the institutional approach, analyze the sector of Russian movements and determine the mechanism of their institutionalization in the information and communication on the Internet in the information age. The sector of Russian movements includes the following types: virtual movements which have not analogy outside the Internet; social movements which are active in a constant reality and which use resources of the Internet (global and local movements); mobs; forums, chats, e-mail. Social movements are an indispensable part of what we call globalisation. They are subdivided into two groups according to the range of activities/actions: global (international) and local (within one country/nation) unions.

\section{Global and local movements}

Individuals' global network movements are becoming influential bodies in the conditions of new world order formation. Network movements (unions) is the sum-total of organizations and movements of the same or different orientation whose participants are integrated by a common goal over space and time. They possess universal objectives. Network movements are represented as direct and indirect forms of interaction. Religious and secular global networks have an organizational nucleus, activists, supporters and they operate in social space. These are not always the unions with the numerous social bases. Some of the movements refer themselves to international movements. They are of global character as they pursue objectives concerning the whole humankind. In sociological science, global unions are represented as cultural movements, for instance, Gospel Protestantism, "Opus Dei", "Soka Gakkai".

International social movements such as "The Red Cross", "Doctors Without Borders", "Greenpeace", "Amnesty International", "Human Rights Watch",

* Corresponding author: volnatmax@ volsu.ru 
"Reclaim the Street" have an opportunity to impact upon global order as their participants possess some transborder understanding and here communication networks are well established. The global nature of the units is revealed in their activities which connect the transnational level, everyday life sphere (the solution of regional problems) and the level of national states (participation in the procedures of representative democracy on a national level). Due to the globalisation processes, the activity of world civic movements has risen for the last few decades.

Such global movements as the International social movement "Transformation", the social movement of socio-psychological aid "Retree", "For countryside life", "Kindness to children of the world", "The people's initiative" exist in the virtual world and they are referred to indirect forms of interactions, but the Russian community is very little informed of their activities. Greenpeace has gained its fame thanks to its campaigns and their wide broadcasting in Russian mass media. Though the activity of the organization in question is well-known abroad, it still does not make a great impact on social life in Russia. There is a lack of awareness of Russian citizens in activities of such movements.

In modern Russia, local unions play a considerable role. They include women's, ecological, youth, national, national-cultural and other movements. They are formed as a challenge to the values unification and aimed at keeping one's own traditions, protecting individual and group interests. Local movements consist of the representatives of some community, setting specific goals before themselves. Unlike global unions, they are created to solve actual problems, concerning individuals, small social groups and layers of the society. They operate within one country. Local movements have their own specific features that are pre-determined by historical traditions, national mentality, the peculiarities of political system and other characteristics.

In the context of globalisation of the world community, local movements are being transformed under the influence of external factors. For instance, new movements in Germany have ceased to represent the interests of individual groups (according to demographic, ideological and professional criteria). During the last decade, a number of unions started protecting some intertwined objectives and universal (global) ideas. The movements have different forms of organization; they use a different strategy of activities in a community. First of all, their representation in mass media is of great importance to them (demonstration of a certain point of view, expert assessment, subjective outlook) and it enables them to make a statement and play a certain role in a global video clip.

\section{Network movements}

Social Movements in the Internet Age "are all interwoven inextricably with the creation of autonomous communication networks supported by the Internet and wireless communication" [1]. Network unions play an important role in Russian society in the early XXI century. Social movements are aimed at representing the interests of social groups and layers of society. Their emergence is conducive to the revival of traditions of charity, to the development of new institutionalized practices. Unions are developing through individuals' intensive activities and they obtain step by step their sustainable character. A great part of people's lives is dedicated to constant interactions revealed in social structures. Modern society is penetrated by numerous networks of formal and informal institutions, by virtual Internet networks etc. In the authors' opinion the social network of public movements is characterized as a structure of relations among coalitions, regulatory bodies and other entities as well as a special type of link between organizations and their members. The networks of unions are new structures in contemporary Russia that are conducive to integration, mobilization of the population to be able to protect their rights and freedoms and are an indispensable element of institutionalization in a civic society. Network formation and growth is an indicator of the globalization process as well as of the modernization society 'from below', by means of consolidation of the efforts of a large number of people. On the macro level, where the movement is represented as an actor, the network is defined through the properties of individuals' unions and the specifics of links arising among individuals in Russian society. On the micro level the inner structure of a union is taken into consideration as well as its functioning, leaders' and participants' activities. The attributes of different movements as social network actors are ideological, material and financial resources, political and social orientation as well as structural clarity.

Both internal and external links form "a network structure". Networks are mobile and changeable [2]. If their links are characterized by intensiveness, duration and sustainability, then the union will function efficiently. The more movements' networks are developed, the less they are dependent on a certain situation and the greater influence they will make on some political processes.

According to the range of activities, most local unions are referred to local movements. However, according to their structure, they represent the sum- total of organizations and movements. They are united with the purpose of solving specific social, political or economic problems. For instance, a network of volunteer movements includes a movement called "Healthy generation", "Healthy Petersburg is the youth's choice", "Drug addiction prevention centre", the network of youth initiatives, regional public organization "The Red Cross" and others.

Veteran unions, movements on the protection for the disabled, women's and volunteer unions are of network character. Rallies, festivals, forums and other events are conducive to the creation and institutionalization of network unions, the activities of many of them is going to be long-term. The forum "Social Petersburg" is aimed at the development of the third sector in Russian society. It is worthy of note that OSI Assistance Foundation carries out the sponsorship of this and other events. Western organizations (Amnesty International, Human 
Rights Watch and others) are conducive to the development of the third sector unions in modern Russia. They cooperate closely and maintain non-commercial organizations' activities. Russian society do not pay enough attention to the problems to do with the institutionalization of civic society.

In recent years in Russia, such direction of volunteer activity as search of the gone children gains popularity. Today there is a full-fledged movement, which purpose is assistance in the organization of search for missing people. Representatives of the movement conduct they activity in daily reality and actively use Internet resources. The most popular associations conducting volunteer search work are: the commonwealth of volunteers "Search of the gone children" and search and rescue group "Lisa Alert". The commonwealth of volunteers "Search of the gone children" has been created in 2009 for combination of efforts of volunteers who help to look for the gone children in Russia and also in neighboring countries (Ukraine, Belarus, Kazakhstan). In the activity, the commonwealth does not replace police and the Ministry of Emergency Situations but only promotes that work, for which special services do not have enough resources. To search for children, they involve the most different methods, from the notification of Internet users to search on the area [3]. The search and rescue group "Lisa Alert" has been created in the fall of 2010. The main task of group consists in search of the gone people. For lifetime "Lisa Alert" with the assistance of volunteers, more than 20 thousand people have been found live. Unique techniques of search are developed, the structure of group allowing to react most effectively to all types of losses of people is created: adults, children, teenagers, elderly with age mental disorders, injured, lost in the wood, in the city, kidnapped persons. The group has the "hot line of search for the gone children" which works every minute. Its functioning is ensured by more than 80 volunteers from different regions of the country. "Lisa Alert" gives preventive classes in safety for children and adults. Persons 18 years of age or over with any level of physical training and degree of entertaining can take part in activity of group. The group has "searchers", information coordinators of search, operators of the hot line, instructors of a group of prevention [4].

\section{Virtual movements in the information age}

In the last decades, in the conditions of formation of information society in virtual space of the Internet, the important role belongs to social movements. These movements are organized by participants for the purpose of drawing attention to a current problem by means of innovative technologies. The official sites, blogs, forums, groups on social networks give an opportunity to create the movement without big expenses, to expand the social base and to involve people in virtual or real social actions. The virtual type of activity distinguishes similar associations from movements which conduct real activity. Leaders of movements actively apply forms of virtual interaction.

The sector of the Russian virtual movements is presented by the following types of associations: the virtual movements which have no analog out of the Internet; social movements which conduct activity in constant reality and actively use Internet resources. Treat the virtual movements: Strategic social movement "Russia 2045", All-Russian social movement "Statehood and Spiritual Revival of Sacred Russia", All-Russian social movement "Preobrazheniye", Social movement "on May 9", etc. Relevant information is located on the websites of movements. Forums where each participant can leave the comments are regularly held. Such movements organize actions, use means for mobilization of the population in virtual reality. The virtual movements enjoy popularity at political leaders. They are created with the purpose to draw attention to a hot topic, to designate a social problem and to define the public relation to this problem with the help of virtual activity, innovative technologies, network communications. Participants follow rules and norms stated in virtual documents. The innovative nature of activity of participants and small expenses is attractive during an institutionalization of the movement (time, money, etc.).

The information architecture occupies a special place in the process of institutionalization of movements. Information architecture includes the organization of the websites, online communities, structuring information space. Access to content, easy search of information, high speed of finding information make virtual movements' sites simple and convenient for potential participants of events.

Today, people use Internet resources to improve the quality of life and save time. The scale of the spread of the Internet has reached almost all kinds of human activities, including charity. The main tools of Internet charity are help sites, forums of various thematic focus and social networking projects. On the forums, there are special threads or topics requests for support. Help groups are organized in social networks and users leave notes statuses and news on their personal pages. Participants often send messages to attract as many people as possible to help. The most demanded today are groups of help to sick people, in most cases - children. The approximate scheme and the main conditions of assistance by means of the Internet are given below.

First, a topic or a help group on the issue is being created on the social network or forum. The group can be created by the beneficiary, one's relatives or volunteers. Indispensable condition is the indication of a contact information of the head of group.

Secondly, the complete description of a problem and the circumstances forcing the person to ask for the help is given. Photos, the scanned copies of supporting documents are published. If the person needs treatment, documentary recorded diagnoses, accounts on treatment from medical institutions are provided.

Thirdly, on an Internet resource assistance requisites are specified. As a rule, for convenience of philanthropists, several variants of translation of means 
are offered. The main of them: transfer to the settlement account, transfer to the plastic card, transfer to mobile phone number (now mobile network operators provide service of a conclusion of money), transfer of funds for an e-wallet (the most popular e-wallets - Yandex.Money and "WebMoney").

Fourthly, for broader coverage of audience volunteers distribute messages with a request for the help. The help can be different: dissemination of information, production of leaflets, search of sponsors and funds, monetary help. Very often participants of group organize charity auctions and fairs, which are held both internally and remotely. If the fair is held in reality, then volunteers will organize in the cities an action, at which they sell various things (hand-made articles, clothes, pastries, etc.). The funds raised from sale are transferred to the beneficiary by means of one of the payment options stated above. When holding a remote fair of a condition don't change except that the offered goods are spread in the form of the photo and persons interested can get him by mail. The seller also reports the raised funds for assistance to the beneficiary. Fifthly, as money transfers are received, receipt reports are published on the website or in the group. As a rule, such reports are provided daily. Along with it, reports on expenditure of the received means are surely published, the scanned copies of checks or the photo of the bought things, medicines are provided.

Sixthly, in group or on the website there is a separate subject where people can leave records about the funds transferred by them, comments, the words of support [5].

Today the Internet acts as an effective resource which allows one to distribute information on a problem and to carry out fund raising in the fastest terms.

Thanks to the Internet, the opportunity to help others has become more accessible to a wide range of individuals. Today, many of the organization who do charity work, use Internet technologies to interact with sponsors, attracting volunteers, as well as to raise funds to assist the beneficiaries.

Besides, in the information age different movements use virtual reality. Virtual movements were arranged with the purpose of attracting attention to a particular topic and determining the public relations while indicating actual problems in virtual reality. They integrate people through communication technologies. The theme, the rules and regulations are specified in the virtual documents and an innovative activity is attractive for the participants.

Strategic public movement "Russia 2045" [6], Russian public movement "For the State and spiritual Revival of holy Russia" [7], Russian public movement "Transformation" [8] are virtual movements. Such movements organize forums, actions, participate in charity, try to mobilize the population in virtual reality. Everyone can take part in virtual events [9] or leave his own comments on the web of the social movement.

Planned mass flash mobs run occasionally and are also referred to virtual movements. Well elaborated scenarios are specific features of such movement. For instance, M. Jackson fan-mob is a dance movement dedicated to the memory of the singer. It has been held in 10 countries of the world including Russia. The participants of the event rehearsed a dance from a video clip called "Thriller" by M. Jackson with instructors involved for video-aids. The records are placed in social networks [10].

A flash mob is a form of unplanned collective activity. This movement is unstable and short-term. Participants organize events independently online. Leaders develop the script online for real-time event. Participants receive instructions. Flash mob "Russia in the Windows. Novosibirsk 2015" has a social orientation. It was organized by the leader of the ecological movement "There is not dirt here" [11].

Flash mobs are unplanned, amorphous movements. They include leaders, agents and ordinary participants who perform informal rules and set a common purpose. Participants are linked emotionally, have the general element (ribbon, umbrella, balloon), perform the same actions. They form a certain communion for a short time. Participants choose an organizational form of their movement and use some mechanism of institutionalization. In virtual reality, the mechanism of institutionalization includes definition of the name of the movement, creation of a web site, dissemination of actual information about events in virtual and constant reality.

\section{Conclusion}

At present, network movements are a new form of participating in socio-political life. They represent complex structures, which elements are characterized by contents and orientation. Such unions have the advantage of relatively simple organizations and movements with specific regard to a structure. Networks enable people to rapid mobilization of population, to directing people's efforts to the solution of specific social problems regarding all the members of a community. Thanks to its extensions over space and time, they have greater chances to a successful outcome. Network movements are known for their innovative character, as they tend to use new communication technologies. This is conducive to a fast information transmittance as well as to engaging populations in different acts. The population exchange their opinion, obtain information thanks to the availability of such popular networks as 'In a Contact', Facebook, Twitter etc. Along with blogs, social networks are used by movements as a tool to mobilize their supporters. Everyone has an opportunity to become a participant on an official website of some unions.

In the modern society, the mass media plays a special role. Public movements spread successfully their ideas by means of innovative technologies. The Internet enables certain movements to expand a social base, to use different ways of interaction with various coalitions, to implement new forms of activities (forums, round tables, the reports/speeches by the leaders of an organisation or a movement). The consolidation of a number of movements into a network structure takes place by means of forums, social networks and the leaders' official websites. 


\section{References}

1. M. Castells, Networks of Outrage and Hope: Social Movements in the Internet Age. (Cambridge: Polity Press,2012)

2. A. Katkina Science Journal of VolSU. History. Area Studies. International Relations 21(1), 129136, (2016)

3. O. Karagodina, Questions of the theory and practice 8-2(34), 75-78, (2013)

4. The commonwealth of volunteers "Search of the gone children", [Electronic document]. URL: https://vk.com/poiskdetei (date of access: 09.04.2018)

5. "Lisa Alert", [Electronic document]. URL: http://lizaalert.org/ (date of access: 09.04.2018)

6. Strategic public movement "Russia 2045", [Electronic document]. URL: http://www.2045.ru/ (date of access: 25.12.2017)

7. Russian public movement "For the State and spiritual Revival of holy Russia" [Electronic document]. URL: http://dvizhenietvorca.ru/ (date of access: 16.01.2016)

8. Russian public movement "Transformation" [Electronic document]. URL: http://www.existense.ru/ustav (date of access: 19.01.2016)

9. Public movement "Vote for Santa Claus", [Electronic document]. URL: http://www.dedmoroz-talisman.ru/ (date of access: 14.02.2017)

10. Michael Jackson Flash Mob, [Electronic document]. URL: http://www.lookatme.ru/flow/allposts/tantsyi/71000-michael-jackson-flash-mob (date of access: 6.12.2016)

11. Russia in the Windows. Novosibirsk 2015. Flash mob. Dmitry Sapelkin, [Electronic document]. URL: http://novosibirsk2020.ru/video/124/ (date of access: 23.01.2016) 